\title{
Effect of Adjuvant Homeopathy with Usual Care in Management of Thrombocytopenia Due to Dengue: A Comparative Cohort Study
}

\author{
Debadatta Nayak $^{1}$ Vishal Chadha ${ }^{2}$ Shruti Jain ${ }^{1}$ Priyanka Nim ${ }^{1}$ Jyoti Sachdeva ${ }^{1}$ Garima Sachdeva ${ }^{1}$ \\ Kumar Vivekanand ${ }^{1} \quad$ Anil Khurana ${ }^{1} \quad$ Sunil M. Raheja ${ }^{2}$ Raj K. Manchanda ${ }^{1}$
}

1 Epidemic Cell, Central Council for Research in Homoeopathy,
New Delhi, Delhi, India
2 Dr. Hedgewar Aarogya Sansthan, New Delhi, Delhi, India

Homeopathy 2019;108:150-157.
Address for correspondence Debadatta Nayak, MD (Hom.), Central Council for Research in Homoeopathy, New Delhi 110058, Delhi, India (e-mail: drdnayak@gmail.com).

\begin{abstract}
Keywords

- dengue

- thrombocytopenia

- homeopathy

- Crotalus horridus

Background Dengue is an emerging threat to public health. At present, no clear modalities are available for the prevention and management of thrombocytopenia due to dengue. This article reports the clinical outcomes of integrative homeopathic care in a hospital setting during a severe outbreak of dengue in New Delhi, India, during the period September to December 2015.

Methods Based on preference, 138 patients received a homeopathic medicine along with usual care $(\mathrm{H}+\mathrm{UC})$, and 145 patients received usual care (UC) alone. Assessment of thrombocytopenia (platelet count $<100,000 / \mathrm{mm}^{3}$ ) was the main outcome measure. Kaplan-Meier analysis enabled comparison of the time taken to reach a platelet count of $100,000 / \mathrm{mm}^{3}$.

Results There was a statistically significantly greater rise in platelet count on day 1 of follow-up in the $\mathrm{H}+\mathrm{UC}$ group compared with UC alone (mean difference = 12,337; $95 \%$ confidence interval $[\mathrm{Cl}], 5,421$ to 19,$252 ; p=0.001$ ). This trend persisted until day 5 (mean difference $=14,809 ; 95 \% \mathrm{Cl}, 1,615$ to 28,$004 ; p=0.02$ ). The time taken to reach a platelet count of $100,000 / \mathrm{mm}^{3}$ was nearly 2 days earlier in the $\mathrm{H}+\mathrm{UC}$ group compared with $\mathrm{UC}$ alone (H+UC: 3.44 days \pm standard error of the mean [SEM] 0.18; $95 \% \mathrm{Cl}, 3.08$ to 3.80 ; UC: 5.28 days \pm SEM 0.29 ; $95 \% \mathrm{Cl}, 4.71$ to $5.86 ; p<0.001$ ). Conclusion These results suggest a positive role of adjuvant homeopathy in thrombocytopenia due to dengue. Randomized controlled trials may be conducted to obtain more insight into the comparative effectiveness of this integrative approach.
\end{abstract}

\section{Introduction}

Dengue is the most common mosquito-borne viral disease in the world and around 50 million dengue infections occur each year. In the South-East Asian region, the case fatality rate is $1 \%$, but in Myanmar, India, and Indonesia it ranges from 3\% to $5 \%{ }^{1}$ Dengue is associated with significant morbidity and mortality. It is endemic in many parts of India including its capital, New Delhi, which is an important metropolitan hub for major

received

July 22, 2018

accepted after revision

November 10, 2018

published online

March 5, 2019

financial and socio-cultural exchange, offering challenging threats to current public health infrastructure. In the recent past, an upsurge of dengue cases in New Delhi posed a significant menace to the existing dengue control policies. ${ }^{2}$ The reported incidence of dengue, as per the National VectorBorne Disease Control Program of India during 2015, was 15,867, with 60 deaths. ${ }^{3}$ However, the actual economic and disease burden of dengue in India is substantially more than official reported cases. ${ }^{4}$

Copyright $\odot 2019$ The Faculty of Homeopathy
DOI https://doi.org/ 10.1055/s-0038-1676953. ISSN $1475-4916$. 
Dengue has several hematological manifestations, including thrombocytopenia and increased bleeding risk. Thrombocytopenia is reported in $79 \%$ to $100 \%$ of patients with dengue. ${ }^{5-7}$ The proportion of dengue patients receiving platelet transfusion ranges from $7 \%$ to $50 \%$, as reported in studies from Trinidad and Tobago, India, Taiwan, and Singapore. ${ }^{8}$ Platelet transfusion, though administered to $22 \%$ to $50 \%$ of adults in various settings, could be inappropriate in around $23 \%$ of patients. ${ }^{9}$ In the absence of major bleeding in dengue with thrombocytopenia, prophylactic platelet transfusion, with an intention to prevent hemorrhagic complications, is questionable. ${ }^{10} \mathrm{~A}$ recent global survey of physicians indicated the heterogeneity of approaches to the use of platelet prophylaxis in dengue patients and variations in clinical practice, with a lack of evidence in this area. ${ }^{11}$ This wide range reflects varying local practices and general lack of consensus with regard to the management of thrombocytopenia in dengue. ${ }^{6}$ Thrombocytopenia, one of the important diagnostic criteria for dengue, is being proposed as an important predictive marker for complications, as studies have shown that lower platelet count correlates with higher complication rate. ${ }^{12}$ Several convergent studies have shown that the death rate in dengue fever is six-fold higher in individuals whose platelet count is below $50,000 / \mu \mathrm{L}^{13}$

With no specific treatment available, current recommended treatment is largely supportive, with careful fluid replacement. There are limited studies in the literature assessing benefits and risks of different modalities for managing thrombocytopenia in dengue infection. ${ }^{14}$ Presently, there is no effective, commercially available, treatment for dengue. ${ }^{15}$ Homeopathic medicine has been advocated for therapeutic use in dengue since the 19 th century. ${ }^{16}$ The homeopathic medical repertory lists 16 medicines for dengue. ${ }^{17}$ Jacobs et al ${ }^{18}$ conducted a pilot study with a homeopathic combination for dengue fever symptoms: the results were inconclusive. Saeed-ul-Hassan et $\mathrm{al}^{19}$ conducted a comparative study to assess the effect of a different homeopathic combination on platelet count and found encouraging results, showing improvement in platelet count. Further, Mahesh et $\mathrm{al}^{20}$ reported homeopathic treatment of 10 dengue fever cases with positive outcome.

During the dengue outbreak of 2015 in Delhi, patients at the Dr. Hedgewar Aarogya Sansthan in-patient department (IPD) were given homeopathic treatment along with usual care (UC) or UC alone. This article reports and evaluates those findings.

\section{Methods}

\section{Study Design}

This was a comparative cohort study of integrative medical practice in a routine IPD setting during an epidemic outbreak of dengue. Only patients who gave informed consent were included in the study. Among them, all patients were offered to receive homeopathy in addition to UC: those who preferred add-on homeopathy received homeopathic medicines along with usual care $(\mathrm{H}+\mathrm{UC})$; the remaining patients received UC only. Two physicians (DN and VC), each with more than 10 years of professional experience, were respon- sible for prescription of medicines. Four homeopathic physicians (post-graduate qualification), each with 5 years of experience, meticulously recorded clinical and laboratory data on a pre-designed case report form. Though these data were collected from routine practice, ethical clearance was obtained from the Institutional Ethics Committee of the Central Council for Research in Homoeopathy, New Delhi.

\section{Study Setting}

The study was conducted in the IPD of Dr Hedgewar Aarogya Sansthan, an allopathic and homeopathic hospital in Delhi, during the dengue epidemic outbreak from September to December 2015. The homeopathic physicians approached the diagnosed/probable dengue patients admitted to the IPD and, after obtaining consent, adjunctive homeopathic treatment was provided.

\section{Participants}

The criteria for inclusion of patients in the study were as per the national standard guidelines: ${ }^{21}$

- Patients compatible with clinical presentation of dengue and seropositive (NS1+ and/or Mac Elisa IgM+), along with thrombocytopenia ('Confirmed case').

- Patients with fever, or recent history of fever ( $<10$ days), with dengue-like symptoms with thrombocytopenia, and from locations where dengue outbreak had been declared ('Probable case').

- Informed consent to participate in the study.

\section{Laboratory Investigations}

As per the standard procedure of the hospital, on admission all patients underwent the basic laboratory investigations such as hemoglobin $(\mathrm{g} / \mathrm{dL})$, packed cell volume, hematocrit, white blood cell, red blood cell, and platelet count. However, platelet count measurement of all the included patients was performed on a daily basis from the day of admission until they reached $100,000 / \mathrm{mm}^{3}$ or more.

\section{Intervention}

Patients in the $\mathrm{H}+\mathrm{UC}$ group were given the indicated homeopathic medicine along with UC. However, with experience gained during treatment of patients, Crotalus horridus was given in cases where indications for an individualized homeopathic medicine were deficient. Those in the UC group were given only UC. After the patients were admitted into the IPD and consent obtained, the indicated homeopathic medicine and UC were given concurrently.

The $\mathrm{UC}^{21}$ consisted of bed rest and cold sponging to keep temperature below $39^{\circ} \mathrm{C}$; anti-pyretics were orally administered to lower the body temperature, and oral fluid and electrolyte therapy were provided for patients with excessive sweating or vomiting. Intravenous fluids were given to patients as per the need of the individual case. Platelet transfusions were done as per need and availability of a platelet donor.

\section{Data Collection}

Clinical data of each patient were recorded systematically on a pre-designed case-recording format for age, gender, fever, 
and key warning signs of illness (e.g., hypotension, intense abdominal pain, and bleeding), duration of fever, length of hospital stay, platelet count, number of platelet infusions, and homeopathic prescriptions.

\section{Outcome}

The primary outcome assessed was change in platelet count during the course of treatment. Secondary outcomes were number of platelet infusions and time taken in days to reach 100,000 platelets $/ \mathrm{mm}^{3}$.

\section{Sample Size and Statistical Analysis}

Sample size was not pre-determined. It involved convenience sampling. All statistical analyses were performed with IBM SPSS v20. Descriptive data/baseline characteristics were expressed in number (\%), mean \pm standard deviation. Categorical data, such as gender, presence of fever, positivity of NS1/IgM/IgG, presence of bleeding, and type of bleeding, were also compared in both the groups. Missing values of platelet count were handled with imputation by the linear interpolation method. ${ }^{22}$ Standard error of the mean (SEM) ${ }^{23}$ was used for statistical inference based on the sampling distribution. Difference of platelet count from baseline to each follow-up was analyzed by independent $t$-test. KaplanMeier analysis was performed for time taken to reach the $100,000 / \mathrm{mm}^{3}$ platelet count. A $p$-value less than 0.05 was considered as statistically significant.

\section{Results}

A total of 283 patients, with fever or history of recent fever and who were admitted to the hospital, were studied (H+UC $=138 ; \mathrm{UC}=145$ ). The flow diagram of patients in the study is given in - Fig. 1. Mean age was $26.3 \pm 11.2$ years and $27.3 \pm 13.2$ years in the $\mathrm{H}+\mathrm{UC}$ and UC groups, respectively. Seventy percent $(n=198)$ were male patients. All patients had history of fever as clinical presentation and only $6 \%$ patients presented with fever during admission. Other clinical features were headache, $18.4 \%,(n=52)$; nausea and vomiting, $38.2 \% \quad(n=108)$; painful abdomen, $44.9 \%$ ( $n=127)$; and bleeding, $48.4 \%(n=137)$. One hundred and twenty-one (42.8\%) patients had positive serology (NS1/IgM/IgG) to dengue virus. Mean platelet count was $26,123 \pm 16,059 / \mathrm{mm}^{3}$ and $27,724 \pm 17,925 / \mathrm{mm}^{3}$ in the $\mathrm{H}+\mathrm{UC}$ and UC groups respectively, and were comparable at baseline. When considering the cases for which dengue serology was performed, the mean platelet counts of $\mathrm{H}+\mathrm{UC}$ and UC were also comparable at baseline ( $\mathrm{H}+\mathrm{UC}$ $=24,481 \pm 17,495 / \mathrm{mm}^{3}, \quad \mathrm{UC}=25,551 \pm 12,945 / \mathrm{mm}^{3}$; $p=0.70)$. The baseline characteristics are reported in -Table 1.

\section{Platelet Count}

Platelet count of all patients under study was checked every day. There was a significant rise in platelet count on day 1 of follow-up in the $\mathrm{H}+\mathrm{UC}$ group compared with UC alone (mean difference $=12,337 / \mathrm{mm}^{3} ; 95 \% \mathrm{CI}, 5,421$ to 19,252 ; $p=0.001$ ). This trend persisted until day 5 (mean difference $=14,809 / \mathrm{mm}^{3} ; 95 \% \mathrm{CI}, 1,615$ to 28,$004 ; p=0.02$ ). Graphical trend lines for the two groups of patients are shown in - Fig. 2.

Sub-group analysis was performed as per bleeding risk in relation to platelet count ${ }^{24}$ in the three categories of high risk $\left(<20,000 / \mathrm{mm}^{3}\right)$, moderate risk $\left(20,000 / \mathrm{mm}^{3}\right.$ to $<50,000 /$ $\left.\mathrm{mm}^{3}\right)$. and mild risk $\left(50,000 / \mathrm{mm}^{3}\right.$ to $\left.100,000 / \mathrm{mm}^{3}\right)$. A significant difference was observed from day 1 (mean

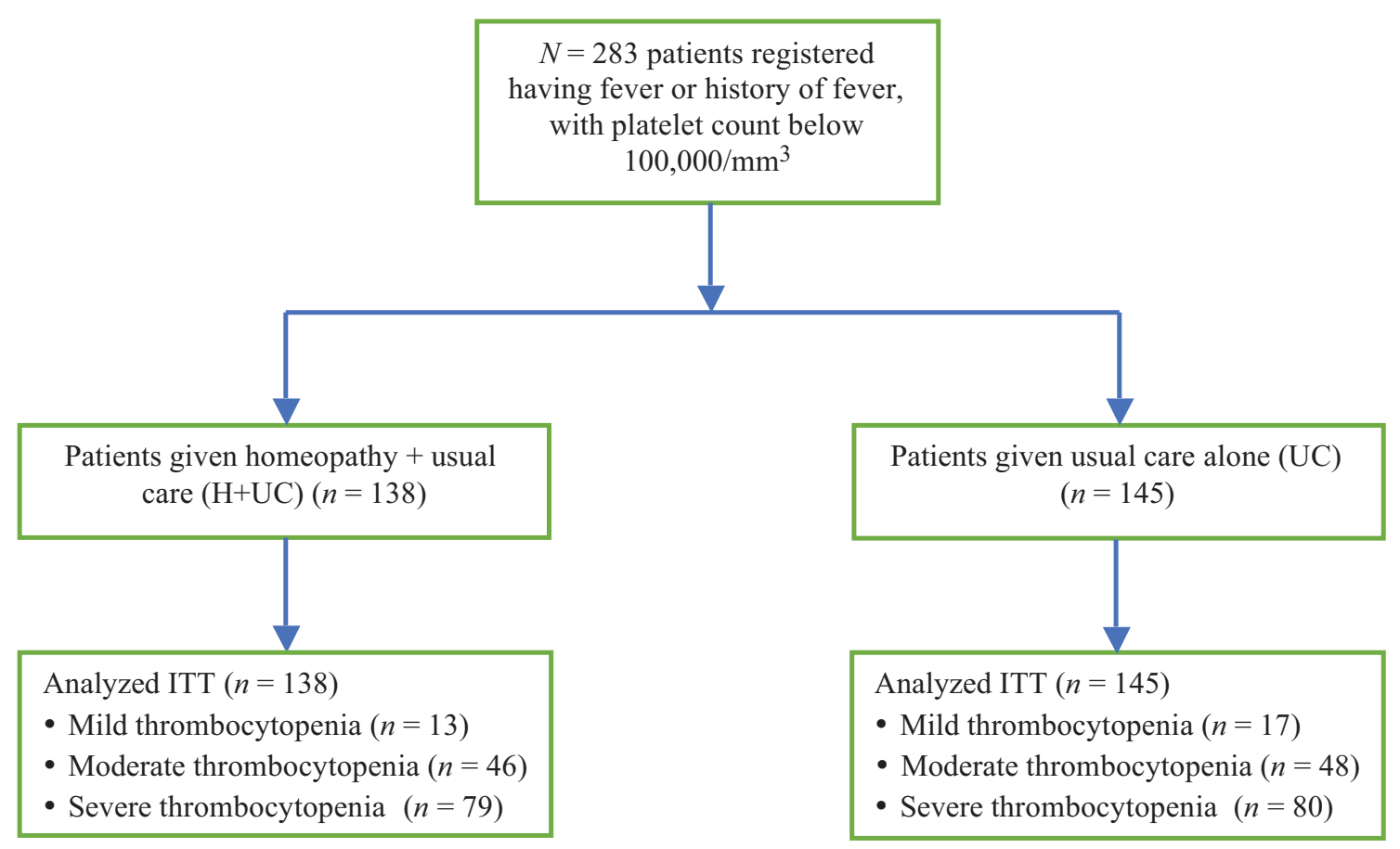

Fig. 1 Flow of patients in the study. 
Table 1 Baseline characteristics of patients

\begin{tabular}{|c|c|c|c|}
\hline Variables & $\mathrm{H}+\mathrm{UC}(n=138)$ & UC $(n=145)$ & $p$-Value \\
\hline Age (years) & $26.3 \pm 11.2$ & $27.8 \pm 13.2$ & 0.27 \\
\hline Male & $106(76)$ & $92(64)$ & 0.02 \\
\hline Female & $33(24)$ & $52(36)$ & 0.02 \\
\hline \multicolumn{4}{|l|}{ Dengue cases } \\
\hline Suspected & $86(62)$ & $76(52)$ & 0.09 \\
\hline Serology positive & $52(38)$ & $69(48)$ & 0.09 \\
\hline Duration of illness (days) & $7.1 \pm 2.4$ & $6.1 \pm 2.7$ & 0.04 \\
\hline Platelet count (cells $/ \mathrm{mm}^{3}$ ) & $26,123 \pm 16,059$ & $27,724 \pm 17,925$ & 0.43 \\
\hline \multicolumn{4}{|l|}{ Platelet count category } \\
\hline $50,000-100,000\left(\right.$ cells $\left./ \mathrm{mm}^{3}\right)$ & $13(10)$ & $17(12)$ & 0.29 \\
\hline 20,000-50,000 (cells/mm³) & $46(33)$ & $48(33)$ & 0.19 \\
\hline Below 20,000 (cells/mm³) & $79(57)$ & $80(55)$ & 0.23 \\
\hline \multicolumn{4}{|l|}{ Fever } \\
\hline Presenting with fever & $4(3)$ & $15(10)$ & 0.01 \\
\hline History of recent fever & $134(97)$ & $130(90)$ & 0.01 \\
\hline Pulse pressure $(\mathrm{mmHg})$ & $37.8 \pm 8.9$ & $33.9 \pm 7.5$ & 0.01 \\
\hline \multicolumn{4}{|l|}{ Blood pressure $(\mathrm{mmHg})$} \\
\hline Systolic & $103.2 \pm 16.9$ & $98.8 \pm 12.2$ & 0.03 \\
\hline Diastolic & $70.1 \pm 9.1$ & $66.2 \pm 8.8$ & 0.08 \\
\hline $\mathrm{Hb}(\mathrm{g} / \mathrm{dL})$ & $14.1 \pm 2.6$ & $13.6 \pm 2.6$ & 0.20 \\
\hline PCV (\%) & $42.3 \pm 7.4$ & $40.0 \pm 7.1$ & 0.01 \\
\hline Hct (\%) & $41.8 \pm 8.8$ & $40.3 \pm 9.2$ & 0.33 \\
\hline WBC (cells $/ \mathrm{mm}^{3}$ ) & $1971 \pm 3514$ & $2320 \pm 3154$ & 0.43 \\
\hline RBC (million cells $/ \mu \mathrm{L}$ ) & $5.23 \pm 4.25$ & $4.69 \pm 1.00$ & 0.28 \\
\hline
\end{tabular}

Abbreviations: $\mathrm{H}+\mathrm{UC}$, homeopathic medicine plus usual care; Hb, hemoglobin; Hct, hematocrit; PCV, packed cell volume; RBC, red blood cell; SD, standard deviation; WBC, white blood cell.

Note: Data presented in $n(\%)$, mean \pm SD.

difference $=54,718 / \mathrm{mm}^{3} ; 95 \% \mathrm{CI}, 22,063$ to 87,373 ; $p=0.002$ ) up to day 2 (mean difference $=59,400 / \mathrm{mm}^{3}$; $95 \% \mathrm{Cl}, 18,184$ to 100,$615 ; p=0.006$ ) in the mild-risk group. Similarly, in the moderate-risk group, a significant difference was found at day 2 (mean difference $=18,331 / \mathrm{mm}^{3} ; 95 \% \mathrm{CI}$, 4,027 to 32,$635 ; p=0.013$ ) and day 3 (mean difference $=20,821 ; 95 \% \mathrm{CI}, 4,828$ to 36,$814 ; p=0.011)$. In the highrisk group, however, the significant difference was found at day 2 only (mean difference $=17,533 / \mathrm{mm}^{3} ; 95 \% \mathrm{CI}, 6,655$ to 28,$411 ; p=0.002$ ).

Further, analysis of dengue sero-positive cases showed a statistically significantly greater increase in platelet count on day 2 of follow-up in $\mathrm{H}+\mathrm{UC}$ compared with UC alone (mean difference $=8,522 / \mathrm{mm}^{3} ; 95 \% \mathrm{CI}, 2,286$ to $14,759 ; p=0.008)$.

\section{Time to Reach $100,000 / \mathrm{mm}^{3}$ Platelet Count}

A Kaplan-Meier curve was drawn to compare the time taken to reach a platelet count of $100,000 / \mathrm{mm}^{3}$ (-Fig. 3). We observed that the patients in the $\mathrm{H}+\mathrm{UC}$ group reached a platelet count of $100,000 / \mathrm{mm}^{3}$ nearly 2 days earlier than UC alone (H+UC: $3.44 \pm$ SE 0.18 days; $95 \% \mathrm{CI}, 3.08$ to 3.80 ; UC alone: $5.28 \pm$ SE 0.29 days; $95 \% \mathrm{CI}, 4.71$ to $5.86 ; p<0.001$ ).

\section{Platelet Transfusion}

A total of $45.2 \%$ ( $n=128)$ of patients received platelet transfusion. Among them, 66\% $(n=85)$ belonged to the high-risk category (i.e., platelet count $<20,000 / \mathrm{mm}^{3}$ ), out of which 42.3\% $(n=36)$ patients were from $\mathrm{H}+\mathrm{UC}$ and $57.6 \%(n=49)$ patients were from UC. No significant difference was observed for platelet transfusion across the risk groups. Out of 159 (56\%) patients who had platelet count $<20,000 / \mathrm{mm}^{3}, 27.6 \%$ $(n=44)$ patients received prophylactic transfusion without bleeding symptoms. A graphical comparison of number of platelet units transfused between the groups is given in - Fig. 4 .

\section{Medicines Prescribed}

Sixteen homeopathic medicines were prescribed to the patients. Of these, 112 patients (81.2\%) received Crotalus horridus. The next most-prescribed medicines were Phosphorus (4 patients, 3\%) and Nux vomica, Pulsatilla nigricans, and Pyrogen (3 patients, $2.1 \%$, for each). 
154 Homeopathy for Thrombocytopenia Due to Dengue Nayak et al.

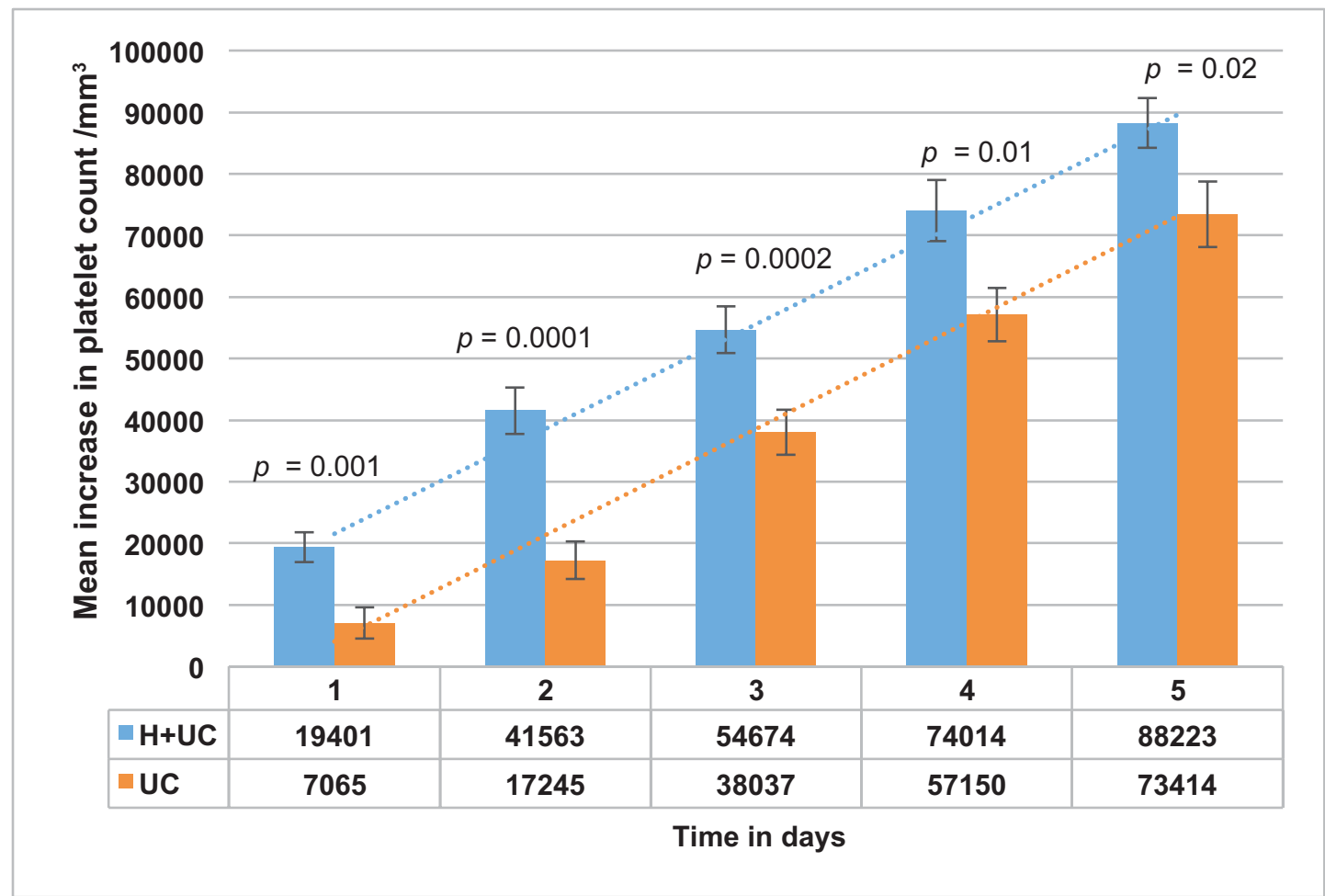

Fig. 2 Difference (rise) in mean platelet count from baseline at different days. H+UC, homeopathic medicine plus usual care. Data show mean and SEM.

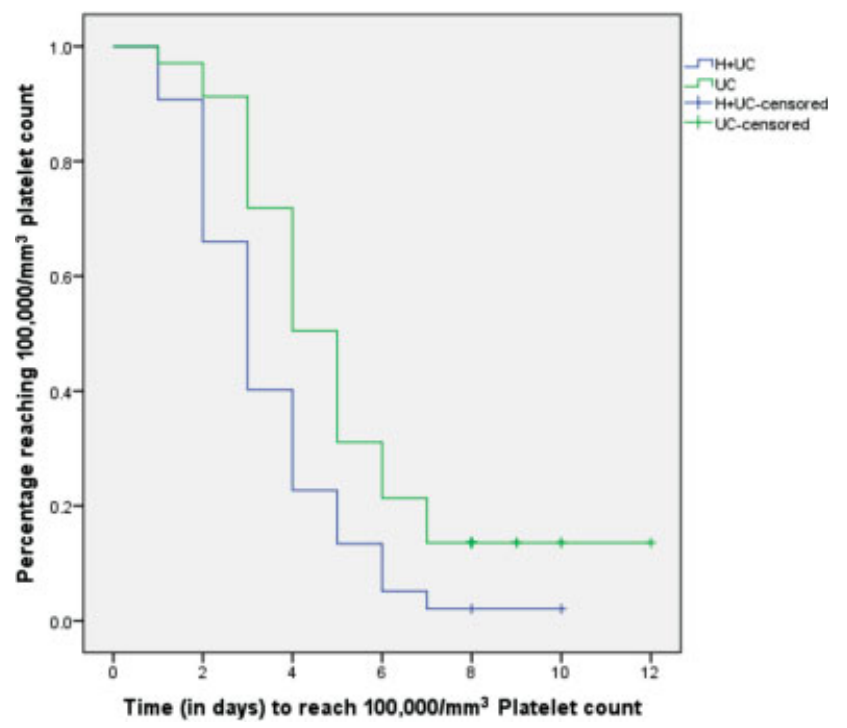

Fig. 3 Kaplan-Meier estimates of time required (days) to reach $100,000 / \mathrm{mm}^{3}$ platelet count. H+UC, homeopathic medicine plus usual care.

\section{Discussion}

Our study suggests that thrombocytopenia of patients with fever or history of recent fever during dengue epidemic can significantly improve with integrative management. The data reflect routine practice in managing thrombocytopenia

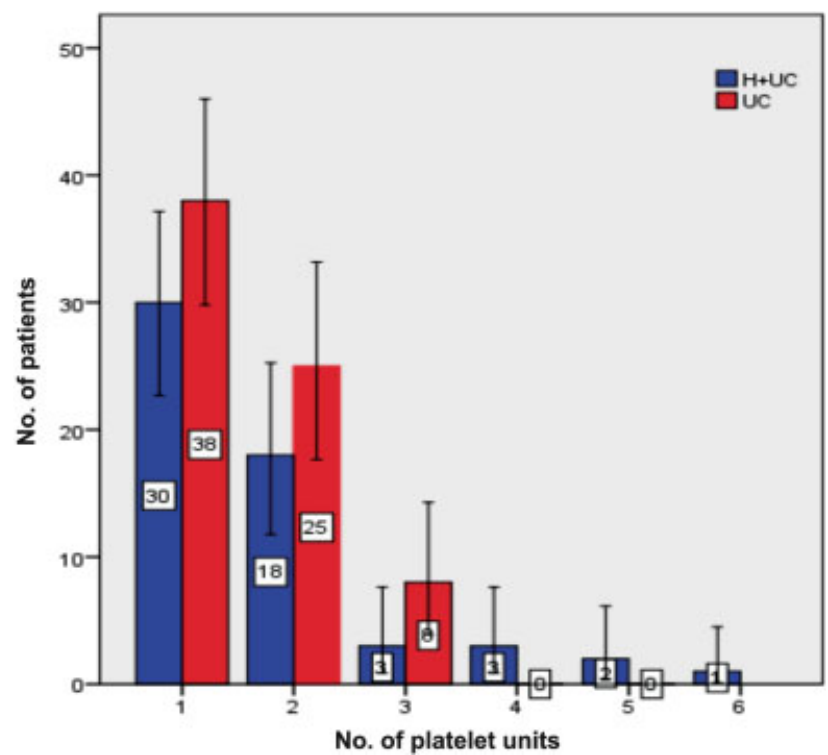

Fig. 4 Between-group comparison of number of platelet units transfused. $\mathrm{H}+\mathrm{UC}$, homeopathic medicine plus usual care. Data show no. of patients along with $95 \% \mathrm{Cl}$.

due to dengue with homeopathic medicines along with usual care. With $\mathrm{H}+\mathrm{UC}$, the platelet counts were seen to increase earlier than with UC alone.

Healthcare during an epidemic outbreak is always a challenge, and more so in developing countries such as India. Much of India lies in the tropics and is therefore susceptible 
to outbreaks of various diseases including dengue. Due to its large population, it is challenging for health service providers to treat thrombocytopenia. Studies from different parts of India report high percentages of inappropriate transfusions, ranging from $13 \%$ to $71 \%$ in dengue epidemics. ${ }^{25}$ Further, in India, blood transfusion services are highly fragmented, and only $35 \%$ of blood units are separated into components. Thus, during explosive outbreaks of dengue when there is sudden surge in demand for platelet products, managing platelet inventories becomes a challenge as the transfusion facility also caters for oncology patients who are major consumers of the same platelet products. ${ }^{26}$ As regards preventive measures, a tetravalent vaccine is commercially available. ${ }^{27}$ However, the drawback of this vaccine is its limited efficacy and potentially severe side-effects ${ }^{28}$ and thus has limited use in clinical practice. ${ }^{29}$ In our study, there was no statistical evidence that the number of platelet infusions was reduced in association with adjuvant homeopathy.

No clear guidelines exist for the management of thrombocytopenia. The practice of platelet transfusion has been adapted into standard clinical practice in the management of hospitalized dengue patients. ${ }^{30}$ As per the WHO guidelines, ${ }^{31}$ platelet transfusion is indicated in dengue patients having hemorrhage with or without thrombocytopenia and as prophylaxis in those whose platelet count is below $10,000 / \mathrm{mm}^{3}$ in the absence of active bleeding. In this study, in the high-risk platelet category $\left(<20,000 / \mathrm{mm}^{3}\right)$, transfusion was required in $42.3 \%$ of patients $(n=36)$ after starting homeopathy treatment compared with 57.6\% $(n=49)$ in the UC group; however, the difference was not statistically significant. There were $56 \%(n=159)$ patients who had platelet count $<20,000 / \mathrm{mm}^{3}$, out of which $27.6 \%$ $(n=44)$ patients received prophylactic transfusion without bleeding symptoms, which is a smaller proportion than reported for an observational study conducted on transfused and non-transfused dengue patients. ${ }^{8}$

Our results show that the difference in mean rise in daily platelet count from baseline until 5th day was greater in the $\mathrm{H}+\mathrm{UC}$ group as compared with UC. A comparative study, conducted in Pakistan using a homeopathy combination, found a daily rise in platelet count as compared with standard maintenance therapy. However, the latter study was conducted on mild-risk patients only. ${ }^{19}$ In another comparative study of prophylactic transfusion versus supportive care alone, no difference in mean daily platelet count was found between the two groups. ${ }^{8}$ However, our study, having the same assessment parameter, showed significant difference in favor of adjunctive homeopathy ( $p<0.05$ ).

The addition of homeopathy treatment to usual care seemed to improve daily platelet count of dengue patients but had equivocal impact on the requirement for platelet transfusion. These results may be clinically relevant in a platelet crisis during a dengue epidemic. Our results may form the basis of larger clinical studies to evaluate the potential of homeopathy in dengue patients. It is thought that the platelet count correlates with the severity of the infection and may contribute to the risk of developing hemorrhage, a well-recognized complication of dengue.
Because of this, prophylactic platelet transfusions are used in some settings to reduce the risk of hemorrhage. There is currently no evidence to support this practice; moreover, platelet transfusions are costly and sometimes harmful. ${ }^{8}$

Even though there is a poor correlation of bleeding with platelet counts, it is a major reason for alarm in both patients and physicians during a confirmed epidemic. Low platelet counts are often the reason for hospitalization and inappropriate platelet transfusions in many patients, resulting in further increased morbidity. 8,32

The clinical experience acquired while following this cohort allowed us to implement the specific management protocol of prescribing Crotalus horridus in cases of thrombocytopenia, where clear indications for an individualized homeopathic medicine were deficient due to use of medications under usual care. Crotalus horridus was successfully used in a yellow fever outbreak in Philadelphia in $1853,{ }^{33}$ which has a very similar pathogenesis to dengue-that is, fever, hemorrhage, and low platelet count. ${ }^{34}$ About $88 \%$ of the $\mathrm{H}+\mathrm{UC}$ group received Crotalus horridus, which is unique to our study. Jacobs et $\mathrm{al}^{18}$ and Saeed-ul-Hassan et $\mathrm{al}^{19}$ both used a homeopathic combination of multiple medicines in their studies. In the combination used by Saeed-ul-Hassan et al, ${ }^{19}$ Crotalus horridus was one component among 10 drugs; a significant difference in platelet count was noticed on the sixth day of treatment. Jacobs et al's ${ }^{18}$ study targeted dengue fever rather than dengue hemorrhagic fever, and Crotalus horridus was not a component of the six-medicine combination used by them. Mahesh et al, ${ }^{20}$ in a series of 10 dengue fever cases, prescribed homeopathic medicines based on individual characteristics. An individualized homeopathic prescription requires the diagnosis of disease as well as of patient, which is not always easy in emergency situations such as epidemics and resource-poor settings. The effect of Crotalus horridus in management of thrombocytopenia due to dengue can further be validated in rigorously designed studies. As dengue has different strains of viruses and their virulence also varies from outbreak to outbreak, Crotalus horridus may have limited effect with change in virus strain and also in virulence.

Our results are likely to be biased by several factors. Our study primarily registered adults in Delhi, India, and our findings should not be generalized to Indian children or to patients in other geographical regions. Second, this study collected data from patients in routine practice; therefore, there was the possibility of not obtaining all the investigational values for all the patients. Third, serology for dengue was not performed in $57 \%$ of patients. Nevertheless, the predictive power of clinical diagnosis will be high during an epidemic because of increased background prevalence of the disease. Moreover, women were under-represented in our study (30\%), though the female gender is a risk factor for bleeding in dengue. ${ }^{35}$ Consequently, referral patterns and diagnostic procedures might bias the patient sample and clinical characteristics. In addition, we lacked serotype information of dengue viruses, as well as information on immune status, for a substantial number of patients. There is also the possibility of preference bias, as only patients who preferred to take adjuvant homeopathic intervention received it along with usual 
care. Effect of patient preference varies with setting. ${ }^{36}$ Our study was conducted in an IPD setting and the outcome was an objective/quantitative parameter; therefore, any preference bias may have been minimal.

\section{Conclusion}

Our results suggest a positive role of adjuvant homeopathy in thrombocytopenia due to dengue. Randomized controlled trials may be conducted to add more insight into this integrative approach.

\section{Highlights}

- One hundred and thirty-eight patients took homeopathy along with usual care $(\mathrm{H}+\mathrm{UC})$ and 145 patients were given usual care (UC) alone.

- Comparative analysis showed significantly greater rise in platelet count on day 1 of follow-up in the $\mathrm{H}+\mathrm{UC}$ group compared with UC alone.

- The time taken to reach a platelet count of $100,000 / \mathrm{mm}^{3}$ was nearly 2 days earlier in the $\mathrm{H}+\mathrm{UC}$ group compared with UC alone.

- These results suggest a positive role of adjuvant homeopathy in thrombocytopenia due to dengue.

\section{Funding}

This study was funded by the Central Council for Research in Homoeopathy, New Delhi, India.

\section{Conflict of Interest}

None declared.

\section{Acknowledgments}

This study would not have been possible without the tireless work and support of physicians, nurses, and support of medical services and paramedical teams, laboratory services of the Dr. Hedgewar Aarogya Sansthan, New Delhi. We also acknowledge the cooperation of patients who agreed to take adjuvant homeopathy along with usual care. Further, the authors acknowledge Mrs. Maya Padmanabhan and Mr. Arvind Kumar, Statistical Assistants, for their support in statistical analysis. The assistance provided by Dr. Rupali Dixit Bhalerao, Research Associate, CCRH, for data management and cleaning, is acknowledged. Authors are thankful to Dr. Roja Varanasi, Research Officer (H)/Scientist-II, CCRH for her critical comments on the draft manuscript. Mrs. Rajni and Mr. Deepak are acknowledged for their secretarial assistance. Moreover, we extend our gratitude to Dr. Piyali Dasgupta, Associate Professor, Marshall University, for input while drafting the manuscript.

\section{References}

1 World Health Organization. Dengue guideline for diagnosis, treatment, prevention and control. Geneva: World Health Organization; 2009

2 Vikram K, Nagpal BN, Pande V, et al. An epidemiological study of dengue in Delhi, India. Acta Trop 2016;153:21-27
3 National Vector Borne Disease Control Program. Dengue. Govt. of India. Accessed January 9, 2019; Available at: http://nvbdcp.gov. in/index4.php?lang=1\&level=0\&linkid=431\&lid=3715

4 Shepard DS, Halasa YA, Tyagi BK, et al; INCLEN Study Group. Economic and disease burden of dengue illness in India. Am J Trop Med Hyg 2014;91:1235-1242

5 Chaudhary R, Khetan D, Sinha S, et al. Transfusion support to dengue patients in a hospital based blood transfusion service in north India. Transfus Apheresis Sci 2006;35:239-244

6 Lee MS, Hwang KP, Chen TC, Lu PL, Chen TP. Clinical characteristics of dengue and dengue hemorrhagic fever in a medical center of southern Taiwan during the 2002 epidemic. J Microbiol Immunol Infect 2006;39:121-129

7 Sharma A, Charles K, Chadee D, Teelucksingh S. Dengue hemorrhagic fever in Trinidad and Tobago: a case for a conservative approach to platelet transfusion. Am J Trop Med Hyg 2012;86:531-535

8 Lee TH, Wong JG, Leo YS, et al. Potential harm of prophylactic platelet transfusion in adult dengue patients. PLoS Negl Trop Dis 2016;10:e0004576

9 Lye DC, Archuleta S, Syed-Omar SF, et al. Prophylactic platelet transfusion plus supportive care versus supportive care alone in adults with dengue and thrombocytopenia: a multicentre, open-label, randomised, superiority trial. Lancet 2017;389: $1611-1618$

10 Kurukularatne C, Dimatatac F, Teo DL, Lye DC, Leo YS. When less is more: can we abandon prophylactic platelet transfusion in Dengue fever? Ann Acad Med Singapore 2011;40:539-545

11 Whitehorn J, Rodriguez Roche R, Guzman MG, et al. Prophylactic platelets in dengue: survey responses highlight lack of an evidence base. PLoS Negl Trop Dis 2012;6:e1716

12 Jayanthi HK, Tulasi SK. Correlation study between platelet count, leukocyte count, nonhemorrhagic complications, and duration of hospital stay in dengue fever with thrombocytopenia. J Family Med Prim Care 2016;5:120-123

13 Chua MN, Molanida R, de Guzman M, Laberiza F. Prothrombin time and partial thromboplastin time as a predictor of bleeding in patients with dengue hemorrhagic fever. Southeast Asian J Trop Med Public Health 1993;24:141-143

14 Chikkaveeraiah SK, Reddy R, Kumar A. A prospective observational study of dengue fever with thrombocytopenia with reference to treatment. Int J Res Med Sci. 2016;4:902-907

15 Nedjadi T, El-Kafrawy S, Sohrab SS, Desprès P, Damanhouri G, Azhar E. Tackling dengue fever: current status and challenges. Virol J 2015;12:212

16 Cowperthwaite AC. Dengue. Textbook of the Practice of Medicine. Chicago: Halsey Bros. Co; 1904

17 Murhy R. Homeopathic Medical Repertory. 1st Indian ed. New Delhi: IBPS; 1994

18 Jacobs J, Fernandez EA, Merizalde B, Avila-Montes GA, Crothers $D$. The use of homeopathic combination remedy for dengue fever symptoms: a pilot RCT in Honduras. Homeopathy 2007; 96:22-26

19 Saeed-ul-Hassan S, Tariq I, Khalid A, Karim S. Comparative clinical study on the effectiveness of homeopathic combination remedy with standard maintenance therapy for dengue fever. Trop J Pharm Res 2013;12:767-770

20 Mahesh S, Mahesh M, Vithoulkas G. Could homeopathy become an alternative therapy in dengue fever? An example of 10 case studies. J Med Life 2018;11(01):75-82

21 Government of India. Guidelines for clinical management of Dengue fever, dengue haemorrhagic fever and dengue shock syndrome. National Vector Borne Disease Control Program. 2008. Available at: http://www.nvbdcp.gov.in/Doc/Clinical\%20Guidelines.pdf. Accessed April 19, 2018

22 Noor NM, Al Bakri Abdullah MM, Yahaya AS, Ramli NA. Comparison of linear interpolation method and mean method to replace the missing values in environmental data set. Mater Sci Forum 2015;803:278-281 
23 Lee DK, In J, Lee S. Standard deviation and standard error of the mean. Korean J Anesthesiol 2015;68:220-223

24 Jayashree K, Manasa GC, Pallavi P, Manjunath GV. Evaluation of platelets as predictive parameters in dengue Fever. Indian J Hematol Blood Transfus 2011;27:127-130

25 Choudhury N. Blood transfusion in borderless South Asia. Asian J Transfus Sci 2011;5:117-120

26 Chaurasia R, Zaman S, Chatterjee K, Das B. Retrospective review of platelet transfusion practices during 2013 dengue epidemic of Delhi, India. Transfus Med Hemother 2015;42:227-231

27 Villar L, Dayan GH, Arredondo-García JL, et al; CYD15 Study Group. Efficacy of a tetravalent dengue vaccine in children in Latin America. N Engl J Med 2015;372:113-123

28 Halstead SB, Aguiar M. Dengue vaccines: are they safe for travelers? Travel Med Infect Dis 2016;14:378-383

29 Halstead SB, Russell PK. Protective and immunological behavior of chimeric yellow fever dengue vaccine. Vaccine 2016;34: 1643-1647

30 Pallavi P, Ganesh CK, Jayashree K, Manjunath GV. Unfurling the rationale use of platelet transfusion in dengue Fever. Indian $\mathrm{J}$ Hematol Blood Transfus 2011;27:70-74
31 World Health Organization Country Office for India. National Vector Borne Disease Control Programme. National Guideline for Clinical Management of Dengue Fever. Government of India; 2014

32 Garg P. Utility of clinical improvement and platelet count recovery time in counseling children hospitalized with suspected dengue in a resource poor setting. J Clin Diagn Res 2008;2:1149-1154

33 Neidhard C. On the efficacy of Crotalus horridus in yellow fever; also in malignant, bilious, and remittent fevers: with an account of Humboldt's prophylactic inoculation of the venom of a serpent, at Havana, Cuba. New York, NY: William Radde; 1860

34 Young PR, Ng LFP, Hall RA, Smith DW, Johansen CA. Arbovirus infections. In: Farrar J, Hotez PJ, Junghanss T, Kang G, Lalloo D, White NJ, eds. Manson's Tropical Infectious Diseases. 23rd ed. London: W. B. Saunders; 2014:129-161

35 Chamnanchanunt S, Kanagaraj D, Thanachartwet V, Desakorn V, Rojnuckarin P. Early predictors of clinically significant bleeding in adults with dengue infection. Southeast Asian J Trop Med Public Health 2012;43:890-899

36 King M, Nazareth I, Lampe F, et al. Impact of participant and physician intervention preferences on randomized trials: a systematic review. JAMA 2005;293:1089-1099 